\title{
Employability Through Experiential Delivery of Intercultural Communication Skills Online
}

\author{
Izzy Crawford ${ }^{1}$, Stephanie Swartz ${ }^{2}$, Susan Luck ${ }^{3}$, Belem Barbosa ${ }^{4}$ \\ ${ }^{1}$ School of Creative and Cultural Business, Robert Gordon University, United Kingdom, \\ ${ }^{2}$ Mainz University of Applied Sciences, Germany, ${ }^{3}$ Graduate School, Pfeiffer University \\ North Carolina, USA, ${ }^{4}$ University of Aveiro, Portugal.
}

\begin{abstract}
International trade, enabled by rapid technological advances, has had a profound effect on the way employees work and communicate in a borderless, virtual environment. Within this context, classroom collaboration through online virtual teams can be an effective strategy to enhance intercultural and employability skills. Research in this area advocates that using digital media to connect students with international classrooms is an easy and efficient way to develop intercultural competence. In this paper we describe and present the results of one such initiative. The authors have designed and implemented virtual and experiential intercultural communications assignments across four countries: Germany, Portugal, Scotland, and the United States. By creating virtual teams and then simulating a real-world team project, we have been able to study how students work with, and react to, teammates from other cultures. We explored students' views and opinions on the expected outcomes of their international experience in virtual teams and the potential impact of online intercultural learning experiences on their future employability. The findings suggest that collaborative online international learning (COIL) can help to develop the kind of soft skills that employers value and need in the globalized workplace.
\end{abstract}

Keywords: intercultural communication; curriculum design; collaboration online. 


\section{Introduction}

Globalization is an economic reality for organizations of all shapes and sizes. According to Fortune Global 500 (https://fortune.com/global500/2019/), "The world's 500 largest companies generated $\$ 32.7$ trillion in revenues and $\$ 2.15$ trillion in profits in 2018. Together, this year's Fortune Global 500 companies employ 69.3 million people worldwide and are represented by 34 countries." The importance of globalization is echoed by the World Bank (https://www.worldbank.org/en/topic/smefinance) who state that "SMEs account for the majority of businesses worldwide and are important contributors to job creation and global economic development. They represent about $90 \%$ of businesses and more than $50 \%$ of employment worldwide."

Hence, acquiring and developing adequate soft skills to work in multicultural teams is essential for students to become employable in today's workplace. Gibb (2014) stressed the relationship between soft skills and employment success, and Balcar (2016) recommended that education systems pay more attention to the development of skills according to employers' needs. In fact, as O' Brien et al. (2016) explained, soft skills are the ones that create competitive advantage and are therefore necessary for success in the implementation of technical (hard) skills. One of the reasons is that these skills are more transferable and thus relevant to the highly flexible contexts employees work within nowadays (Albandea, 2018). As Robles (2012) noted, "soft skills are employability skills that are transferrable in many jobs" (p. 458).

Communication, collaboration, teamwork, leadership, responsibility, and interpersonal skills are among the most cited soft skills. In fact, the literature presents several listings of soft skills, many of them based on the opinions and evaluations of managers and executives (e.g., Crawford et al., 2011; Robles, 2012). However, we argue that due to the dominant globalized economy, intercultural skills are of utmost importance for professionals and consequently for students, and teaching and learning strategies. According to ESCO (https://ec.europa.eu/esco/portal/browse?type=Skill), transversal competences include social interaction skills, which, in turn, encompass intercultural competence, defined as to "understand and respect people who are perceived to have different cultural affinities, and respond effectively and respectfully to them". Diamond et al. (2011) asserted that it is imperative that managers know how to work collaboratively in multi-cultural teams and are able to manage complex interpersonal relationships. Then, international experience is expected to be particularly valuable for students, especially the ones in management areas, as employers need professionals that can compete in global marketplaces (Diamond et al, 2011). 


\section{Experiential learning online and intercultural competence}

Since today's businesses operate globally, with locations and offices worldwide, the days of being fairly confident that employees within a division will share one's culture appear to be over. Without the ability to understand and work within the framework of each other's cultural communication, an employee's career may falter.

Although universities are placing an increasing emphasis on providing theoretical education in intercultural competence, which Deardorff (2009) defined as possessing the necessary attitudes and reflective behavioral skills; studies from the workplace show that this increase in emphasis has not yielded desired results. In fact, the U.S. National Association of Colleges and Employers 2018 Jobs Outlook Survey found, among other results, that the percentage of graduating seniors and young employees who believed that they were proficient in global/intercultural fluency was much higher than the percentage view of employers (BauerWolff, 2018). Therefore, in order to increase employability, students need to go beyond theory and utilize intercultural skills to behave effectively and appropriately in intercultural situations.

As teachers and researchers, the authors believe that part of the disconnect lies in the difference between learning about intercultural differences and actually experiencing those differences. One of the strongest arguments in defense of internationalization at home is democratizing the benefits of mobility. Indeed, not all students are able to travel overseas, and the programs that foster student mobility are able to support only a small percentage of them. Therefore, the continuous development and spread of technology opens opportunities for many more students to engage in intercultural experiential learning (Bhat and McMahon, 2016).

\section{A Virtual Teams Project Spanning Four Countries}

An example of one such COIL project was conducted by the authors in the fall 2018. Four instructors from universities in the United States, Germany, Scotland and Portugal engaged their students in a six-week virtual team project. The participants were undergraduate and graduate students of varying disciplines from Business Administration, Marketing and Public Relations to Applied Computer Sciences, ranging in age from 20 to 40, coming from diverse ethnic backgrounds and possessing various levels of English knowledge. While there are conflicting opinions concerning the effectivity of heterogeneous groups, the authors agree with Gorgônio et.al. (2017) that they are more effective, share more knowledge and improve mutual learning as well as more accurately reflect the diverse workforce graduates must navigate today. 
During the launch of the project, the instructors tested out the collaborative software students were to utilize themselves and introduced them to the class, illustrating some of the technological challenges and how they can be overcome. According to Starke-Meyerring and Andrews (2006) the importance of instructors as role models through the intensity of and interest in their own collaborations cannot be underestimated. To this end, the instructors met once a month for a virtual conference and kept each other abreast of difficulties students were experiencing.

The first phase of the project involved students building rapport. The importance of building relationships and developing trust for successful virtual multicultural team collaborations is supported by Molinsky and Gundling (2016). Students were asked to provide personal information and create an animated film about their team using the tool Powtoon. The second phase of the project focused on a mutual assignment involving the research and analysis of the online presence of a global company. SLACK was a useful platform for coordinating information, and the audio/video software of ZOOM provided a reliable communication platform. The synchronization of the assignment goals and deadlines across all classes was fundamental to the virtual teams' project. This was also imperative in the third phase of the project where students presented their findings and made recommendations as to how their companies could improve their use of social media and presence online. These were presented using the online platform Prezi and papers were written collaboratively through the use of Google Docs. The requirements and expectations for the presentations and final papers needed to be the same for all classes in order to ensure quality and fair treatment. Using the same grading rosters and carrying out a grading session where all instructors evaluated the submitted work, had a "gelling" effect and lent cohesion and credibility to the virtual teams experience from the students' and the instructors' perspective (Bégin-Caouette, 2013).

\section{Student Perceptions of Collaborative Online International Learning and Employability}

The project was evaluated via an online intercultural competency survey based on the Intercultural Sensitivity Scale created by Guo-Ming Chen and William J. Starosta for the University of Rhode Island (2000). Out of 44 items which Chen and Starosta developed as indicators for the measurement of intercultural sensitivity, we selected 24 items divided into five factors: Interaction Engagement, Respect of Cultural Differences, Interaction Confidence, Interaction Enjoyment and Interaction Attentiveness and asked students to respond to each item on a five-point Likert scale ( $5=$ strongly agree, $4=$ agree, $3=$ uncertain, $2=$ disagree and $1=$ strongly disagree). 
Students were asked to complete this survey before the project began. At the end of the project, students were again asked to complete the survey but this time we included qualitative questions concerning their personal feelings towards the project, what they found most difficult, their satisfaction with the project, and what they would do differently next time. In addition, they were asked to rate the activity and evaluate both their own and their team members, both at home and abroad, concerning commitment and active participation .

The research demonstrated that there were more positive than negative perceptions of the experience overall and it was almost universally regarded as something which employers would value. Participants cited the development of their own soft skills as one of the most significant outcomes of the project, including improved time management skills, willingness to take the lead, active listening and greater empathy for non-native English speakers: "I learned to be more tolerant towards others work dynamics.",

They also said the project had challenged their preconceptions about other cultures and in many cases completely negated them. However, in other instances participants observed differences in ways of working which they attributed to a combination of culture and individual personalities: "I enjoy working with people from different cultures because it affords me the opportunity to step outside myself and see a different way of doing things."

Some felt that trying something new and out-with their comfort zone was a simultaneously exciting and scary prospect. Where the team bonded in a friendly, supportive and safe environment they enjoyed the experience more and were sorry when it came to an end: "We exchanged social media contacts after the project and are still in touch." Many teams functioned better as time went on and familiarity with the context, challenges, tools and personalities grew.

Participants believed that the project had inspired creativity, innovation and 'thinking outside the box' because it forced them in to a new, unfamiliar situation with people they did not know and with limited tutor intervention: "I've learned to adapt to the different mindsets and challenges inherent to people from different cultures."

They regarded effective communication as central to the success of the intercultural project and were able to deconstruct the strengths and weaknesses of their own communications as well as that of their team-mates: "Accents and speech emphasised cultural differences, however I was surprised I could follow and communicate with them."

Despite some initial challenges related to IT reliability and access problems, they enjoyed learning new virtual communication applications and said they would use these online tools more confidently in future as well as being more open to trying new software: "I learned how to work with Slack, Prezi and Zoom - I feel very confident using this in future for work or school." 
The participants experienced significant issues related to time differences, conflicting study, work and personal schedules, varying levels of motivation and language barriers: "I now know how hard it is to manage time frames across time zones, we all had to work round different schedules, work, families as well - time zones just made it more challenging." This sometimes resulted in high levels of frustration, fear of failure and delays.

\section{Conclusion}

As mentioned earlier, employees require greater levels of awareness and understanding of other cultures to operate effectively within a multinational, global context (Diamond et al, 2011). Positive working relationships (often marked by the presence of effective soft skills) with international partners, investors, suppliers, customers, employees and other stakeholders are critical to the sustainability and success of many organisations. Participants frequently cited the development of their own soft skills as one of the most significant outcomes of the COIL project. These soft skills which are tested and cultivated through virtual, experiential learning are highly valued by employers because they are transferable to any workplace context (Albandea, 2018; Robles, 2012). This is also important for employees in an era where portfolio careers are becoming more prevalent and lifelong positions working for the same employer are less common (IMF, 2017). Intercultural projects can also help participants to develop tolerance and respect (Parker, 1999), because participants are likely to encounter a wider range of communication challenges than they would in a local project. The participants in this project experienced significant challenges related to geography, culture, age, experience, time differences, IT reliability, conflicting study, work and personal schedules, personality differences, varying levels of motivation and language barriers.

Despite the challenges, many participants felt the experience was interesting, worthwhile and provided a fresh perspective that they may not have considered otherwise. They felt they had learned a lot about themselves and others: "The project gave me an informative view of the world of operations for a global company - I have a newfound respect for these companies because they have to overcome substantial barriers to be successful." This ability to selfreflect and adapt to new communication environments and situations is something that employers are likely to value as globalization and digitisation continue to accelerate and advance.

Many participants believed that COIL projects are relevant and highly beneficial practice for future employment in the global, digital era and should be more common in the curriculum. "Employers will be keen to have professionals with this specific skill of intercultural communication as it is a real skill." They could see how increased awareness of other cultures, increased confidence in working with people from other countries, greater selfawareness and self-monitoring of individual communication styles, and higher levels of 
tolerance when working in virtual international teams, might help to enhance their own and others' employability.

The survey findings combined with anecdotal evidence obtained through informal discussions between students and staff involved in the project, suggested that overall the project had been worthwhile. However a number of enhancements were identified for future delivery including: evolving and refining the evaluation methods; improving the coordination, timing, composition and support for student teams; incorporating more student touch points to promote engagement; developing more consistent, integrated assessment criteria; and including more frequent multi-way tutor communication. According to Deardorff (2016) a profound intercultural competence assessment must go beyond selfreports, as only the others' perspectives will effectively assess the appropriateness of communication and behaviour. Clearly, assessing the effectiveness of virtual internationalization initiatives is a topic that deserves further attention by academics and researchers, and that will benefit from additional approaches, innovation, and replication to attest what, how, and how much are students developing their intercultural skills by collaborating with their international peers.

\section{References}

Albandea, I. (2018). The Employer Perception of Non-linear Educational Pathways. A Vignette Study with French Employers, Post-Print halshs-01947264, HAL. https://ideas.repec.org/p/hal/journl/halshs-01947264.html

Balcar, J. (2016). Is it better to invest in hard or soft skills? The Economic and Labour Relations Review, 27:4, 453-470. https://doi.org/10.1177/1035304616674613

Bauer-Wolff, J. (2018). Overconfident Students, Dubious Employers. Inside Higher Ed. Retrieved from https://www.insidehighered.com/news/2018/02/23/studystudentsbelieve-they-areprepared-workplace-employers-disagree\#.WpATRGkybjY.linkedin

Bégin-Caouette, O. (2013). Global networked learning environments as eduscapes for mutual understanding. Critical Intersections in Education: An OISE/UT Students Journal, 1, 5470.

Bhat, C. S. \& McMahon, M. (2016). Internationalization at home for counseling students: Utilizing technology to expand global and multicultural horizons. International Journal for the Advancement of Counselling, 38, 319-329.

Crawford, P., Lang, S., Fink, W., Dalton, R., \& Fielitz, L. (2011). Comparative analysis of soft skills: What is important for new graduates. Michigan State University and the University Industry Consortium, 1-24.

Deardorff, D. K. (2009). Implementing intercultural competence assessment, in D. K. Deardoff (Ed.), The SAGE handbook of intercultural competence, 477-491. Thousand Oaks, California: Sage Publications.

Deardorff, D. K. (2016). Outcomes assessment in international education. Global and Local Internationalization, 83-89. Rotterdam, Netherlands: Sense Publishers, 
Diamond, A., Walkley, L., Forbes, P., Hughes, T., \& Sheen, J. (2011). Global graduates into global leaders. London: The Council for Industry and Higher Education and CFE Research and Consulting.

Gibb, S. (2014) Soft Skills Assessment: Theory Development and the Research Agenda, International Journal of Lifelong Education, 33(4) 455-471 https://doi.org/10.1080/02601370.2013.867546

Gorgônio, F. L., Vale, K. M. O., Silva, Y. K. N., \& Silva, H. M. (2017). Grouping students for cooperative and collaborative learning: challenges and trends in virtual learning environments, 2, 51-55. Paper presented at I IEEE World Engineering Education Conference. Retrieved from http://edunine.eu/edunine2017/proc/works/33.pdf

IMF New Economy Forum. (2017). The future of work: Special collection of essays for the IMF annual meetings. Washington, DC. [online] Retrieved from: https://issuu.com/medauras/docs/dc_imf_bookazine_lr

Leask, B. (2016). Internationalizing curriculum and learning for all students. Global and local internationalization, 49-53. Rotterdam, Netherlands: Sense Publishers,

Molinsky, A. \& Gundling, E. (2016). How to build trust on your cross-cultural team. Harvard Business Review. Retrieved from https://hbr.org/2016/06/how-to-build-trust-on yourcross-cultural-team

Parker, W. C., Ninomiya, A. \& Cogan, J. (1999). Educating world citizens: Toward multinational curriculum development. American Educational Research Journal, 36, 117 145.

Robles, M. (2012). Executive Perceptions of the Top 10 Soft Skills Needed in Today's Workplace. Business and Professional Communication Quarterly, https://doi.org/10.1177/1080569912460400

Starke-Meyerring, D. \& Andrews, D. (2006). Building a shared virtual learning culture. Business and Professional Communication Quarterly, 69, 25-49. Association for Business Communication. https//doi.org/10.1177/1080569905285543

O' Brien,W., Belton, S. \& Issartel, J. (2016). Fundamental movement skill proficiency amongst adolescent youth, Physical Education and Sport Pedagogy, 21:6, 557571, DOI: $\underline{10.1080 / 17408989.2015 .1017451}$ 